CCIJ

22,4

In the Summer of 2015, I began to work as the new Editor of Corporate Communications: An International Journal. In 2016, I made a presence at the annual meeting of Corporate Communication International outlining my view of the future for the journal. It is time to refine that vision and to present it to the larger audience of the journal. The vision has two components. The first component is the type of contact that I see as appropriate for the journal. The second component relates to ideas for expanding the format of manuscripts submitted to the journal.

\section{Focus of the journal}

The keywords in the name of the journal are "corporate" and "communication." How those words are defined is essential to delineating the content that is appropriate for the journal. I would like to start by emphasizing a need for the authors to consider the role of praxis in their manuscripts. Praxis can be defined as theory plus action. I see the journal articles as rooted in theory but more than just theory and extended into practice. Practice can mean applications for managers, applications for researchers, or both. You could say I am looking for manuscripts that are utilitarian - have applications. Part of the discussion for any submission should include how the knowledge generated by the article can be used by others. Ideally those others should be managers and researchers but some articles might focus on just one of those targets.

Corporations are frequently viewed as legal entities but I am not focusing on the legal requirements for a corporation. I define corporations more broadly using these three characteristics: a unified group of individuals, related to business, and the qualities associated with a corporation. I believe manuscripts will continue to center on business organizations - companies and firms. However, I also favor a broader view of corporation to include non-governmental organizations (NGOs) which are typically not-for-profit and can include activist organizations. NGOs, for example, are a unified group of people and often have the qualities associated with a corporation. Moreover, the communicative actions of NGOs can have effects on corporations. My feeling is that we can broaden the view of corporation without losing sight of the term completely.

Communication must be central aspect of the research that is submitted. Communication is so broad almost anything can be considered to be communication. However, manuscripts must make communication a central feature of the research and highlight the strategic nature of communication - the purposeful use of communication to achieve objectives. Communication must be foreground and not background in manuscripts. The objectives of study remain vast including written communication, verbal communication, and visual communication. Furthermore, any methodological approach can be used from experimental to critical. Each method will be evaluated for its application to the objective of study with no preconceived notions that favor one method over another. Communication with corporations can focus on internal communication, external communication, or a combination of the two. Again, there is no preference given to either an internal or external communication focus.

I think it is critical that I reveal the criteria I am using when I make the first decision on a manuscript - should it be sent for review. My job at that point is to screen out those manuscripts I do not think fit within the parameters of corporate communication. The screening is critical because manuscripts outside of the journal's purview are difficult to review properly. It is unfair to reviewers and to submitters to ask people to review manuscripts outside of their research experiences.
Corporate Communications: An International Journal Vol. 22 No. 4 ,
pp. $418-419$

C) Emerald Publishing Limite 1356-3289

DOI 10.1108/CCIJ-08-2017-007

\section{Editorial}

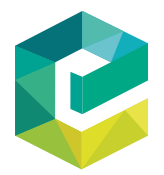




\section{Format of manuscripts}

Editorial

Beginning in 2018, Corporation Communications: An International Journal expands to ten articles per issue. I would like to use that change to expand the format of the manuscripts appearing in the journal. The journal has favored tradition research that creates original knowledge. Reviews are typically not a part of that scenario. I would like to encourage the submission of two different types of review pieces for Corporation Communications: An International Journal. The purpose of including reviews is to provide a resource primarily for researchers but also a summary of key findings for managers.

I am calling the one type of reviews: Future Directions. These will be shorter entries of between 2,000 and 3,000 words and most will be commissioned. By commissioned I mean experts in particular areas will be asked to submit a Future Directions review. The Future Directions provide an explanation and overview of the topic to set up a discussion of future directions for research. I see the Future Directions meeting two needs. First, the articles will expose people to new research areas they did not know about before. My plan for the first few Future Directions is to feature "newer" areas of research. Second, the Future Directions will provide an agenda by suggesting areas for future research that stimulates additional research. My hope is that these Future Directions become valuable resources for those reading the journal. If a person is interested in writing a Future Directions piece, they should e-mail me first so that we can review the idea and decide whether or not to go forward with the idea. There will not be a special category in the submission process marked "Future Directions."

The second type of review will be longer (around 6,000 words) in the format of a systematic review. A systematic review seeks to identify what we know about a research topic and evaluate the quality of the extant research. Not only does the reader learns about past findings but also develops a sense of the research methods used in the field and how well or poorly those methods have been applied in the past. Systematic reviews should include specific criteria for selecting the studies and an explanation of how the articles were evaluated. The evaluation, for instance, could be how the articles were coded or the specific criteria used to evaluate the quality of an article. A systematic review is a great resource for people looking to conduct research in a particular area. The researchers learn what has been done and how it has been done. Systematic reviews can be performed on both quantitative and qualitative data. The last section of the systematic review should indicate where to go next based upon where that research topic has been. Unlike the Future Directions, feel free to submit a systematic review without contacting me. Again, there will be no special designation in the submission process for systematic reviews. If you plan to submit a systematic review, the following links are valuable starting points:

www.stir.ac.uk/media/schools/management/documents/centregradresearch/How \%20to $\% 20 \mathrm{do} \% 20 \mathrm{a} \% 20$ systematic $\% 20$ literature $\% 20$ review $\% 20$ and $\% 20$ meta-analysis.pdf

www.apsu.org.au/assets/Resources/Writing-a-Systematic-Literature-Review.pdf

Timothy Coombs 